\title{
UMA ANÁLISE DE UMA TAREFA AVALIATIVA EM UMA SALA DE LÍNGUA INGLESA REALIZADA COLABORATIVAMENTE
}

\author{
Victor Hugo Oliveira Magalhães \\ Mestrando em Letras e Linguística pela Universidade Federal de Goiás (UFG) \\ victorvhom@hotmail.com
}

\section{RESUMO}

Este artigo investiga as implicações de se realizar uma tarefa avaliativa de maneira colaborativa em uma sala de aula de língua inglesa. Para tanto, usa-se como base o conceito vygotskyano de Zona de Desenvolvimento Proximal, o conceito de scaffolding de Wood, Bruner e Ross (1976), e, finalmente, postulações de diversos autores (CRANDALL, 1990; FIGUEIREDO, 2003; 2006; 2011; dentre outros) sobre a aprendizagem colaborativa. Os dados deste artigo revelaram resultados positivos para além da mera execução da tarefa em questão: os alunos em ação colaborativa sentiramse menos tensos e praticaram inglês entre eles durante a realização da atividade. Isso pode apontar para uma possível vantagem em se realizar avaliações colaborativamente, visto que a avaliação deve ser vista não apenas como medição de conhecimentos, mas como promoção de aprendizagem.

Palavras-chave: ensino de língua estrangeira, aprendizagem colaborativa, avaliação.

\section{ABSTRACT}

This article investigates the implications of carrying out an evaluative task in a collaborative way in an English language classroom. As a basis to reach this goal, I employ the Vygotskyan concept of Zone of Proximal Development, Wood, Bruner and Ross's concept of scaffolding (1976), and, finally, postulations by many authors (CRANDALL, 1990; FIGUEIREDO, 2003, 2006, 2011; among others) about collaborative learning. The data here gathered shows positive results beyond the mere execution of the task in question. The students involved in collaborative action felt less tense and practiced English among themselves during the activity. This could point to a possible advantage of performing evaluations collaboratively, since they should not be seen only as a way to measure knowledge, but as a tool to promote learning.

Keywords: foreign language teaching, collaborative learning, evaluation. 


\section{Introdução}

Ao ingressar em um curso livre de inglês, é comum observar que uma forma de interação muito recorrente é a em pares (aluno-aluno), sendo superada talvez somente pela tradicional interação professor-aluno(s). Essa interação a dois é promovida principalmente em tarefas que envolvem diálogos, tanto livres quanto mais estruturados, sendo, portanto, utilizada mais regularmente em contextos de ênfase da fala. Por vezes essa interação é usada em tarefas de outros tipos, como correções ou mesmo composições de textos em pares. O fato é que o famoso pairwork, ou trabalho em pares, é um dos modos de interação em sala de aula preferidos entre os profissionais de ensino de inglês como língua estrangeira. No entanto, cabe refletir: por que fazemos tanto uso do trabalho em pares?

A razão, ou melhor, a teoria por detrás da prática é uma que não é muito recente, mas que prova sua relevância até os dias de hoje: a teoria sociocultural do desenvolvimento e da aprendizagem. Apesar de muitos professores não se darem conta, é essa teoria creditada principalmente ao estudioso russo Lev Vygotsky que fomenta essa prática pedagógica. Grosso modo, a teoria sociocultural da aprendizagem postula que a interação é a forma pela qual nos desenvolvemos e aprendemos desde muito novos. Preconiza que ao interagirmos, podemos alcançar níveis de conhecimento antes inatingíveis caso trabalhássemos sozinhos. Dessa forma, a teoria não se volta à capacidade individual de cada um, mas ao conhecimento potencial que este indivíduo pode vir a usufruir caso interaja com outros indivíduos. Dado esse panorama teórico, torna-se evidente a importância dos preceitos construtivistas vygotskyanos para o âmbito escolar de forma geral. 
Neste trabalho, mais precisamente, pretende-se avaliar como se dá a interação em pares em regime de colaboração em uma tarefa avaliativa. Percebe-se na prática pedagógica de muitos professores que esses não lançam mão do padrão de interação em pares quando o objetivo é realizar uma avaliação formal dos alunos. Normalmente, atividades avaliativas ou provas são feitas para averiguar apenas a capacidade individual de se produzir conhecimento, e, portanto, requerem que os alunos sejam isolados de qualquer interação. Por meio do uso de conceitos que partem da teoria sociocultural da aprendizagem, tais como a própria zona de desenvolvimento proximal (ZDP) de Vygotsky, o scaffolding (WOOD; BRUNER; ROSS, 1976) e a aprendizagem colaborativa (OXFORD, 1997; CRANDALL, 1999; FIGUEIREIDO, 2003; 2006; 2011), serão analisadas as interações de dois pares durante uma tarefa avaliativa de escrita em que tinham que escrever um texto colaborativamente. Espera-se com isso mostrar a aplicabilidade e implicações da interação colaborativa em pares para tarefas que buscam também avaliar os aprendizes.

\section{A zona de desenvolvimento proximal, scaffolding e aprendizagem colaborativa}

A teoria sociocultural de Lev Vygotsky foi e ainda é revolucionária para os moldes educacionais da nossa sociedade. O psicólogo russo desafiou teorias tradicionais sobre o desenvolvimento e a aprendizagem ao tratar esses dois conceitos como interdependentes e concomitantes (VYGOTSKY, 1998), além de os enxergar sob uma ótica prospectiva, ou seja, "para além do momento atual" (OLIVEIRA, 2000, p. 12). Em outras palavras, o que interessa ao estudioso é o conhecimento em constante processo de evolução, e não o estado hirto do saber de um indivíduo. Essa conclusão nos acerca ao 
conceito de zona de desenvolvimento proximal, ou ZDP. Vygotsky $(1998$, p. 112) concebe a ZDP como

a distância entre o nível de desenvolvimento real, que se costuma determinar através da solução independente de problemas, e o nível de desenvolvimento potencial, determinado através da solução de problemas sob a orientação de um adulto ou em colaboração com companheiros mais capazes.

O que interessa aos adeptos do conceito de ZDP é o que o aprendiz pode produzir com a ajuda de um outro (nível de desenvolvimento potencial), em detrimento daquilo que produziria sozinho sem qualquer tipo de estímulo provindo de uma interação com outro par (nível de desenvolvimento real).

Por mais abrangente que seja, algo que alguns autores (TUDGE, 1990; SWAIN; BROOKS; TOCALLI-BELLER, 2002) questionaram do construto de ZDP de Vygotsky é a pressuposta necessidade de um par mais competente para que haja desenvolvimento satisfatório. Tudge (1990, p. 158), por exemplo, defende que faltou a Vygotsky relativizar as interações para além da díade do par mais competente / menos competente, para além de um fluxo unidirecional da colaboração. Tudge (1990, p. 169) ainda desafia a concepção tradicional da ZDP ao dizer que "não há garantia que o significado que é criado quando dois pares interagem vai estar em um nível superior, mesmo se uma criança é mais competente que outra e está provendo informação dentro da ZDP do par menos competente", e propõe: "ao invés de casualmente supor os benefícios de pôr em par uma criança com um par mais competente, deveríamos prestar mais atenção aos processos de interação em si". Podemos imaginar que, tivesse Vygotsky vivido por mais tempo (morreu 
jovem, aos 38 anos, em 1934), seguramente teria reconsiderado e expandido esses aspectos de sua teoria.

Retomando o que Tudge (1990) diz sobre atentar-nos mais aos processos de interação em si, ao se fazer exatamente isso, muitos autores teorizaram sobre as ações tomadas pelos indivíduos durante interações colaborativas / cooperativas em pares. Perceberam que essas ações muito comumente tinham como propósito dar suporte para que um dos elementos do par pudesse alcançar um nível de conhecimento relativamente próximo de sua capacidade, mas que sem ajuda talvez não conseguiria. O processo no qual se configura esses tipos de ações foi denominado por Wood, Bruner e Ross (1976) como scaffolding, traduzido ao português mais comumente como "estrutura de apoio" (FIGUEIREDO, 2006, p. 15). Traduzido ao pé da letra, scaffolding quer dizer andaime, que é a metáfora utilizada para ilustrar o movimento de se "edificar" ou ainda "criar alicerces", ou seja, criar bases que impulsionem o avanço em uma determinada tarefa.

No geral, o processo de scaffolding prevê um par "controlando elementos da tarefa que estão inicialmente além da capacidade do (outro) aprendiz" (WOOD; BRUNER; ROSS, 1976, p. 89). Esse "controle" deve possuir três características básicas para que as estruturas de apoio tenham resultados positivos na interação em pares. Em Figueiredo (2006, p. 15) vemos que as estruturas de apoio devem ser graduais, contingentes e dialógicas. Graduais, pois devem primeiramente ser implícitas e, se necessário, tornaremse posteriormente explícitas. Devem ser contingentes, visto que a ajuda só deve ser oferecida quando houver real necessidade para ela. As estruturas devem, também, ser dialógicas, tendo em vista que é por intermédio do diálogo que se evidencia a ZDP e o tipo de ajuda a ser oferecida. Dessa forma, fica claro que as estruturas de apoio não se propõem a prover respostas prontas a um dos indivíduos do par, mas instigar aquele que 
ainda não alcançou resultados na tarefa a relacionar o que já sabe com os suportes fornecidos a ele, e daí obter êxito na produção de um novo conhecimento. Podemos concluir então que as estruturas de apoio agem na ZDP, justamente ao aproximar os níveis de desenvolvimento real (o que já se sabe) (VYGOTSKY, 1998) e potencial (o que se sabe a partir da interação com um outro indivíduo) (VYGOTSKY, 1998), promovendo dessa forma o desenvolvimento e a aprendizagem.

As estruturas de apoio, além de gradativas, contingentes e dialógicas, podem também ser caracterizadas em estratégias concretas facilmente detectáveis ao se observar uma interação colaborativa / cooperativa em pares. Wood, Bruner e Ross (1976, p. 98) estabelecem alguns destes níveis de scaffolding:

1. Estabelecimento ou restabelecimento de interesse pela tarefa buscar maneiras de lembrar o par das motivações para a realização da tarefa;

2. Simplificação da tarefa - separar em etapas a tarefa de forma a se progredir aos poucos, porém constantemente;

3. Persistência na busca do objetivo - manter o foco do aprendiz para que se concentre na conclusão da tarefa;

4. Elucidação de aspectos importantes e as discrepâncias entre o que já foi feito e a solução ideal - apontar erros e deslizes e encaminhar o par para uma ação acertada;

5. Controle da frustração durante a busca de soluções de problemas - amenizar efeitos negativos de erros ou fracassos;

6. Apresentação de uma versão idealizada do que será realizado (re)formular a versão acertada para fixação do conteúdo.

Esses níveis, se realizados com a devida atenção e foco no desenvolvimento dentro da ZDP, são de grande valia para aprendizes em configuração de pares, não só pela realização assistida da tarefa em si, mas pelo desenvolvimento de diversas competências sociais que os levarão a ajudar outros indivíduos no futuro. 
Ao se focar na qualidade das estruturas de apoio em uma interação em par, admitimos que o processo da produção de conhecimento nos é mais caro que o resultado obtido por tal processo, e então reconhecemos a aprendizagem colaborativa tanto como relevante quanto como frutífera para os nossos contextos educacionais. Entende-se que na aprendizagem colaborativa, "o que importa não é apenas o sucesso do grupo em realizar uma determinada tarefa, mas a coconstrução do conhecimento" (FORMAN; CAZDEN, 1985, p. 20). Dessa forma, ainda bebendo de Forman e Cazden (1985, p. 331), para uma tarefa ter valor educacional, não é o bastante que simplesmente engaje os aprendizes em uma atividade conjunta, mas deve haver também o diálogo entre diferentes pontos de vista.

Naturalmente, o encontro desses diferentes pontos de vista causa conflitos cognitivos (TUDGE, 1990) que, ao mesmo tempo em que podem criar desconfortos entre os aprendizes, podem fortalecer o comprometimento com a aprendizagem de ambos. Por meio da instauração de uma dinâmica colaborativa em sala de aula, os aprendizes se tornam responsáveis uns pelos outros, aliviando o papel comumente centralizado no professor de fornecedor ou único mediador do conhecimento. Vai-se além da díade aluno/professor (OXFORD, 1997), possibilitando que novas maneiras de interação fomentem novas formas de produção de conhecimento, pois "aprendizes trazem para as interações suas próprias histórias pessoais repletas com valores, suposições, crenças, direitos, deveres e obrigações" (DONATO, 2000, p. 46).

Vários são os benefícios da aprendizagem colaborativa apontados em trabalhos de autores como Forman e Cazden (1985) e Crandall (1999). Entre eles, destacam-se as maiores oportunidades para aprendizes escutarem e produzirem língua; uma maior variedade de atos de fala ou funções de linguagem; oportunidades para aprendizes 
desenvolverem entendimento intercultural, respeito e amizades, assim como habilidades sociais positivas de respeito de opiniões alternativas e alcançar consenso; maior centralização na figura do aprendiz na sala de aula; mais oportunidades para aprendizes desenvolverem habilidades de pensamento crítico; e melhor suporte para aprendizes de língua moverem da interdependência para independência. Quanto aos possíveis problemas, os autores citam as expectativas culturais de papéis esperados do professor e aprendiz; estilos ou preferências de aprendizagens individuais; diferenças de personalidade; apoio em excesso na primeira língua; exposição a modelos imperfeitos de língua e feedback incorreto.

No entanto, alguns desses aspectos ditos negativos são justamente aspectos dos quais a aprendizagem colaborativa se apropria para garantir a diversidade e qualidade da produção de conhecimento na interação. Um exemplo é o "apoio em excesso na primeira língua", que autores como Silva (1999) e Figueiredo (2003) contestam ao determinar que o apoio na primeira língua, ao invés de atrapalhar, ajuda na construção da segunda língua. Silva (1999), por exemplo, argumenta que o uso que os alunos podem fazer da primeira língua vai além da simples tradução de itens linguísticos de um código para outro, na medida em que ela pode possibilitar a construção dos scaffoldings e, consequentemente, a realização da tarefa. Nesse sentido, a visão da L1 como obstáculo para o aprendizado da L2 é, além de um tanto antiquada, exclusiva dos processos interacionais em L1 que podem facilitar a realização de uma atividade e, consequentemente, o entendimento de uma nova estrutura ou item lexical na $L 2$.

Ao observar como se relacionam os conceitos até aqui trabalhados, a saber, a ZDP, o scaffolding e a aprendizagem colaborativa, nos resta considerar sua aplicabilidade em uma tarefa avaliativa. Como bem sabemos, tradicionalmente, avaliações são momentos 
não só individuais, mas solitários e tensos para aprendizes. Isso se dá, geralmente, pela forma rija como as avaliações de desempenho (SCHLATTER; GARCEZ; SCARAMUCCI, 2004) são concebidas, a fim de garantir uma suposta objetividade e padrão nos resultados. Nesse processo, a (inter)subjetividade fica de lado, algo que é caro para a teoria sociocultural de Vygotsky. Assim, percebemos uma discrepância entre a obsessão da averiguação do nível de desenvolvimento real (VYGOTSKY, 1989) nas tarefas avaliativas tradicionais e a indubitável utilidade para o nível de desenvolvimento potencial do aprendiz caso essas avaliações fossem realizadas colaborativamente. A exagerada ênfase no produto desconsidera a tarefa avaliativa como um momento também de aprendizagem (SCHLATTER; GARCEZ; SCARAMUCCI, 2004) e vai contra a afirmação de Swain e Lapkin (1998) de que "a aprendizagem não acontece fora da performance, mas ocorre na performance" (p. 321). Levando essas reflexões em conta, este estudo visa examinar como se realizam os conceitos de ZDP, scaffolding e da aprendizagem colaborativa em uma tarefa avaliativa, através do uso da metodologia apresentada a seguir.

\section{Metodologia}

Este estudo se insere na área de Linguística Aplicada, especificamente tratando dos processos de aprendizagem de $L 2$, e se enquadra dentro de um paradigma qualitativo de pesquisa. A pesquisa qualitativa se define, em linhas gerais, como um paradigma de pesquisa que visa entender como os participantes vivenciam e interagem com um fenômeno em um determinado tempo e contexto, a partir da análise interpretativa dos 
dados gerados (CROKER, 2009). Dessa forma, interpreta-se os dados considerando as subjetividades dos participantes dentro do contexto escolhido.

O estudo foi realizado em uma aula de inglês de um curso livre de idiomas em Goiânia, Goiás. A pesquisa foi proposta a um grupo iniciante de inglês (mais precisamente o primeiro nível do curso) do próprio pesquisador. De um total de dezoito alunos desse grupo, se voluntariaram para a pesquisa seis pares de alunos. No entanto, devido ao escopo do trabalho, foi escolhida somente a gravação de dois pares para a análise de dados. Esses quatro participantes (aqui referidos por seus pseudônimos Joana, Maria, Ayesha, Marcos) tinham níveis variados de proficiência na língua, pois alguns já haviam estudado inglês enquanto outros estavam tendo seu primeiro contato com a língua, e formaram seus pares por razões aparentemente de afinidade.

A tarefa aqui em questão foi realizada em uma das aulas finais do semestre letivo, e tinha como propósito a confecção colaborativa de um texto traçando o perfil de uma personagem anônima a partir de uma imagem (Figura 1). O objetivo é que usassem de sua criatividade coletiva para redigir um texto inventando informações que quisessem, tais como nome, idade, nacionalidade, personalidade e passatempos. Os alunos foram informados antes do começo da tarefa que esta seria de caráter avaliativo, ou seja, contribuiria para a nota final deles. Isso obviamente fez com que os alunos levassem a atividade mais a sério do que uma atividade regular. 
Figura 1 - Estudante muçulmana

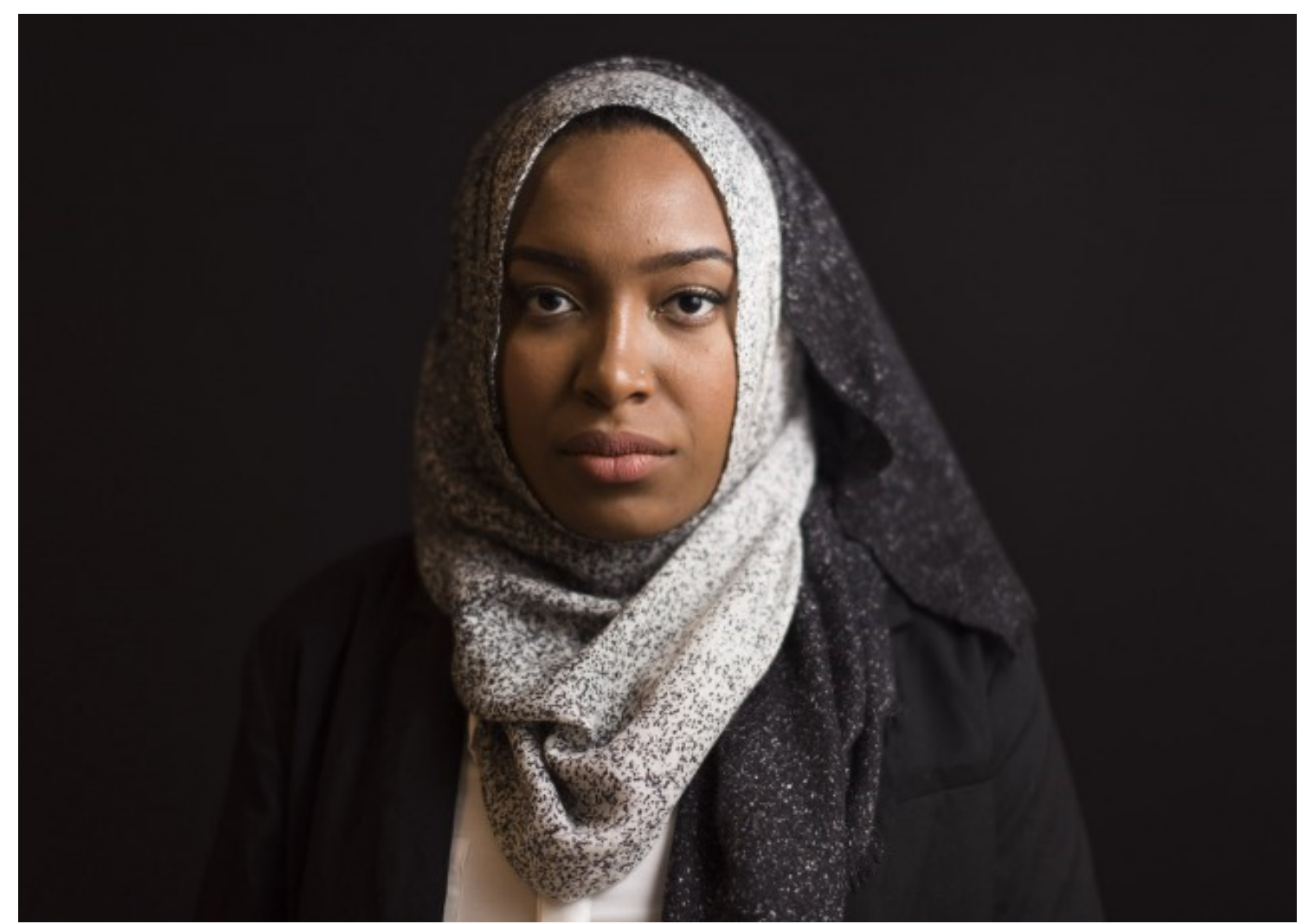

Fonte: Disponível em: <https://dailybruin.com/2016/05/24/muslim-students-to-unveil-truth-behindstigmas-at-the-hijab-monologues/>. Acesso em: 12 ago. 2018.

O professor, na tentativa de ter influência mínima no processo de redação do texto, se limitou a mostrar a imagem e a pedir aos seus alunos que criassem o perfil da pessoa. Nenhum detalhe sobre o tipo de linguagem, gênero textual, itens lexicais ou estruturas gramaticais foi dado, a fim de que os alunos se sentissem livres para utilizar o que já sabiam antes ou internalizaram durante o curso.

Os alunos participantes da pesquisa gravaram suas interações durante a composição do texto por vinte minutos, aproximadamente. Partimos agora para a análise de seus diálogos (através de excertos representados como E1, E2, etc.) sob a ótica dos conceitos provenientes da teoria sociocultural previamente mencionados. Nas seções a seguir focaremos nos três conceitos perpassados na parte teórica desse trabalho: ZDP, estruturas de apoio (scaffolding) e aprendizagem colaborativa. 


\section{Análise dos dados}

À primeira vista, as interações ocorridas durante a realização da tarefa podem ser resumidas como definitivamente ricas em variedade. Os excertos nos mostram que os alunos se engajaram em conversas (FIGUEIREDO, 2003) sobre os procedimentos da tarefa (E1, E4), sobre forma (E3, E5), assim como sobre o conteúdo em si (E1, E2). Essas conversas ocorreram, deve-se dizer, em sua maioria na língua materna, seguramente devido ao nível de proficiência ainda baixo na língua estrangeira. No entanto, é interessante notar que a língua inglesa não é omissa, e aparece em algumas enunciações, inclusive juntamente com o português:

E1 Joana: Vamos falar que ela vive no Brasil. She lives no Brasil.

E2 Joana: What's her profession?

E3 Maria: Eu tinha que falar é assim: “L-I-P-S” (soletra em inglês)

E4 Ayesha: A gente tem que usar alguma coisa negativa também...

E5 Ayesha: $O$ adjetivo antes, né?

Na primeira e terceira fala vemos o uso misto das duas línguas, ao passo que nas demais, com exceção da segunda, percebemos a utilização mais constante do português. Antigamente estigmatizado (SILVA, 1999), o uso da L1 atualmente recebe mais crédito devido ao seu caráter auxiliador na tarefa e doravante na produção da L2. Curiosamente, amostras da língua inglesa apareceram involuntariamente no diálogo dos alunos (E2, E3), o que exibe certo grau de internalização e mesmo conforto em usar a língua estrangeira em um contexto no qual não há pressão para que os alunos usem somente a L2. Nos 
dados acima, podemos dizer então que a função do português foi justamente a de direcionar e organizar a atividade com o fim de se produzir melhor na L2.

Entre os usos das estruturas de apoio analisáveis nos dados, percebemos na E1, por exemplo, que há uma simplificação da tarefa, evidenciando a necessidade de se "quebrar" a tarefa em etapas a fim de facilitar sua execução. Essa divisão ajuda os aprendizes a refletir melhor sobre aspectos mais específicos de cada parte da tarefa, auxiliando-os a, pouco a pouco, construir um texto coeso e correto. Ainda na E1, constatamos a apresentação de uma forma idealizada da língua a ser produzida, ainda que com algum português envolvido. Isso evidencia a necessidade que os alunos têm de reiterar o que foi discutido em par e pô-lo de forma definitiva no texto. Dessa maneira, os alunos acabam por produzir L2 múltiplas vezes, praticando a cada repetição. Nas demais falas, percebemos o uso da L1 para a persistência no objetivo da tarefa (E4) e elucidar aspectos discrepantes entre o que já foi feito ou resta fazer e a solução ideal (E5). Isso aponta que, entre o par, houve interações que os encaminhavam para os próximos passos da tarefa, até sua finalização, ao mesmo tempo em que os alunos também se atentavam para as falhas e erros de suas produções, refletindo sobre seus conhecimentos na L2.

Adicionalmente aos notáveis processos de scaffolding, vale dizer que o uso da L1 é também reflexo dos processos cognitivos internos de cada aluno, e, revelados no diálogo, podem ser melhor trabalhados e dirigidos para decisões mais acertadas, beneficiando-os em uma situação de avaliação. Desse modo, o uso tanto da L1 como da L2 é encorajado, pois o importante é "que ambos os aprendizes iniciem e sustentem interação verbal um com o outro" (BROOKS; DONATO, 1990, p. 268 apud ANTÓN; DICAMILLA, 1999, p. 236). 
Por meio dessa interação verbal, repleta de processos de scaffolding, os alunos podem finalizar da melhor forma possível a tarefa avaliativa.

Em uma atividade colaborativa, os participantes devem, em teoria, participar de forma igualitária, pois ambos detêm igual responsabilidade sobre a tarefa que realizam. No entanto, sabendo das relações de poder que estão presentes em nossas interações, é válido pensar que essas interações nem sempre serão totalmente balanceadas. Enquanto um dos pares (Ayesha e Marcos) apresentou interação de certa forma equilibrada, tomando turnos de duração semelhantes e contribuindo proporcionalmente para a realização da atividade, o outro (Joana e Maria) não demonstrou mesmo padrão interacional:

E6 Maria: Não é "she's a nurse", não?

Joana: Mas é "she's nurse", se não fica "ela é uma enfermeira".

E7 Joana: Small? Estou achando grande os olhos dela.

Maria: Ah, é?

Joana: She has big eyes.

E8 Joana: Como que é lábios?

Maria: Não é lips?

Joana: É? Não sei... Mouth?

Maria: É...

Como vemos, Joana parece tomar as decisões do que entra ou não no texto produzido pelo par, enquanto Maria tem suas sugestões questionadas e finalmente não acatadas por Joana. Ao analisar tal padrão de interação a partir das categorizações de Storch (2001b apud SWAIN; BROOKS; TOCALLI-BELLER, 2002, p. 176), percebe-se que Joana assume a posição de especialista da língua enquanto Maria a de iniciante. Isso se deve ao fato de que, apesar de reconhecer as contribuições de Maria e não 
necessariamente desvalorizá-las, Joana demonstra estar mais no controle da tarefa, realizando o papel de uma espécie de líder, impondo o conteúdo do produto final. Enquanto isso, Maria, no papel de iniciante, dá sugestões de maneira tímida, insegura, aparentemente já esperando uma outra versão de seu par, mesmo estando em muitos casos correta.

No entanto, vale contrapor que concessões e negociações são de fato realizadas, apesar de serem mais raras:

E9 Maria: Her country is poor.

Joana: She doesn't like difficult of her country? Tipo assim, ela não gosta da dificuldade do país dela, mas fica meio idiota.

Maria: Eu queria colocar que o país dela é pobre, com fome, porque aí a gente pode usar hungry.

Joana: Her country is poor... E very difficult for live.

Como vemos, aqui, Maria contribui com uma construção correta na L2 (E9 - her country is poor), além de sugerir a inserção de um novo item lexical: hungry. Joana, por sua vez, inclui parte da contribuição de Maria (her country is poor... e very difficult for live), mas não deixa de incluir a sua ao mesmo tempo, ainda que errada gramaticalmente. Novamente o papel de especialista de Joana (SWAIN; BROOKS; TOCALLI-BELLER, 2002) se sobressai na interação durante a tarefa, mas desta vez com alguma flexibilidade por parte dela.

Idealmente, os papéis assumidos pelos alunos do par devem ser observados pelo professor mediador, a fim de que um deles não domine ou se anule diante de uma tarefa, que, a princípio, deveria conter contribuições iguais de ambos os lados. Tal igualdade nas contribuições é importante para a promoção de uma avaliação mais justa e condizente com o nível de desenvolvimento potencial dos membros do par. Por outro lado, acreditar 
que qualquer troca verbal pode / deve ser inteiramente pacífica, consensual e nãoimpositiva é exageradamente otimista, além de prejudicial a nós mesmos, pois "o conflito cognitivo traz à tona os desequilíbrios que tornam necessária a elaboração cognitiva" (FIGUEIREDO, 2006, p. 25), que nos ajuda a desenvolver e aprender. Isto posto, cabe repensar essa postura ingênua e passiva por uma mais crítica que, ao mesmo tempo em que almeja formas éticas de interação, é consciente das relações de poder que existem na sala de aula.

Um dos fatores mais interessantes ao observar as interações durante a tarefa avaliativa em regime colaborativo deveu-se às implicações afetivas que esta teve nos participantes. No geral, percebeu-se em suas falas certa tranquilidade na construção do texto, sem pressões exageradas e cobrança individual exacerbada:

E10 Joana: Go é ir, e venho? Leave?

Maria: Esse leave assim eu não conheço não... Coloca aí então, a gente tá aqui pra...

E11 Marcos: Depois o teacher corrige.

Ayesha: Ah é, ele vai corrigir, ok!

Nos dois momentos registrados acima, verifica-se uma preocupação menor com a avaliação final do trabalho em relação ao prosseguimento da tarefa. Na primeira fala, é interessante notar a oração inacabada "a gente tá aqui pra...", que parece poder ser completada por "aprender". Maria aparenta reconhecer, por meio da sua afirmação não finalizada, que a tarefa é parte integrante de seu processo de aprendizagem do inglês ao invés de fator determinante de sua capacidade cognitiva. De fato, retirar esse peso da avaliação em sala de aula constitui uma grande vantagem da colaboração em pares nesse 
contexto, pois permite que aprendizes possam se manter mais calmos e enxergar o momento avaliativo dentro do horizonte maior que é sua aprendizagem de L2.

Outro aspecto interessante reside na segunda fala e refere-se à maneira imperturbada em que é enunciado o prospecto de que o professor será o apreciador do trabalho final e que corrigirá os erros e deslizes do texto. Podemos então deduzir que o professor, apesar de figura ainda hierarquicamente mais capacitada para correção e avaliação, é vista como tendo "um papel de mediador da aprendizagem, o que faz com que os alunos se tornem responsáveis pela melhor maneira de dar termo a uma atividade" (FIGUEIREDO, 2006, p. 23). Essa mudança na concepção da figura do professor é marcante se pensarmos nos meios tradicionais pelos quais se costuma avaliar na escola. A correção pelo professor perde seu caráter de rotulação da capacidade do aluno e ganha cunho motivador para que esse aluno evolua e cresça com o que errou. A nota não é mais o limite máximo do conhecimento, mas termômetro do progresso. Através da colaboração, esses paradigmas podem ser quebrados em favor dos alunos e de como enxergam o professor e seu processo de aprendizagem.

Estando mais tranquilos e seguros, os participantes produziram língua que nem mesmo haviam aprendido nas aulas, sentindo-se livres para recuperar conhecimentos prévios ou obtidos fora da sala de aula. O verbo "leave" no E10, por exemplo, foi trazido do nível de desenvolvimento real de Joana, negociado por Maria, e utilizado sem mesmo a certeza de sua adequação ao texto. Se seu uso é verdadeiramente correto ou não, o fato relevante é que essas alunas já agiram em suas ZDPs e aprenderam algo novo. Joana por ter experimentado o uso de um item léxico que conhecia previamente, e Maria por conhecer um novo item léxico através de outro aprendiz. Considerando os papéis de especialista e iniciante que Joana e Maria desempenharam durante a tarefa, citamos 
Figueiredo (2003, p. 129), que aponta que "a interação não ajuda apenas os alunos menos experientes: ela leva também os alunos mais experientes a descobrir novas formas de aprender".

Ao lançarem mão de sua criatividade ao se arriscarem com itens lexicais e estruturas ainda não internalizadas, esses alunos provam que se sentiram tão confortáveis em uma tarefa avaliativa como em uma tarefa sem tal caráter. Isso corrobora com os benefícios da atividade colaborativa apontados por Figueiredo (2011), tais como o aumento da autoestima, a diminuição da ansiedade, a capacidade de se correr riscos e maior motivação para realização da atividade. Além desses, outro benefício notável na relação dos participantes com a tarefa realizada foi o sentimento de autoria e propriedade que demonstraram:

E12 Marcos: O que vamos botar? A gente escreve assim?

Ayesha: Nessa primeira parte aqui, eu queria colocar... nossas primeiras aulas, né? Que era nome, sobrenome, endereço, telefone, e-mail... todas essas informações pessoais.

Na fala transcrita acima, Ayesha trata o texto do par de forma a transparecer uma preocupação genuína com o conteúdo dele. Ao mesmo tempo, é dela e de Marcos a escolha dos conteúdos que estarão presentes no texto, evidenciando o princípio da independência de produção dos aprendizes em uma tarefa colaborativa. Todos os quatro participantes demonstraram um alto nível de autonomia na criação de seus textos, criando produções deveras diferentes uma da outra. Constata-se, portanto, que a avaliação, se realizada de forma colaborativa, muito tem a contribuir com a formação de aprendizes mais autônomos e criativos na L2. Além disso, a avaliação colaborativa incentiva que alunos engajem em processos de scaffolding que agirão em suas zonas de 
desenvolvimento proximal e os auxiliarão no seu desenvolvimento e aprendizagem. Finalmente, somada a esses benefícios, a percepção da avaliação de forma menos ferrenha e mais contributiva para a aprendizagem também é de grande valia.

\section{Considerações finais}

Em vias de considerações finais neste trabalho, retomo a pergunta realizada no primeiro parágrafo sobre a razão do recorrente uso do trabalho em pares em sala de aula de língua estrangeira. Depois das reflexões promovidas neste texto, assevera-se os benefícios trazidos por esse modelo de interação ao contexto do ensino de língua estrangeira, justamente por proporcionar aos aprendizes uma forma rica de aprender, tanto durante como depois da interação. Isso porque a "língua é simultaneamente um meio de comunicação e uma ferramenta para o pensamento" (SWAIN; LAPKIN, 1998, p. 320). Isto é, ao mesmo tempo em que dialogamos com um outro que possui conhecimentos distintos aos nossos, trocando informações e consequentemente aprendendo, também organizamos e consolidamos nossos saberes através do uso da língua.

Voltando-nos especificamente para interação em pares de forma colaborativa, percebemos vantagens que vão além da aprendizagem concomitante à interação e passamos para contribuições para a autonomia do aluno de língua estrangeira com seu processo de aprendizagem, por exemplo. Ao prever que aprendizes, postos em contexto de interação, possam dar vazão a sua criatividade e negociar a maneira pela qual desejam realizar determinada tarefa, podemos constatar que a colaboração permite que esses alunos se tornem mais conscientes de suas responsabilidades e potenciais como 
aprendizes. Adicionalmente, resta desconfigurado o papel do professor como figura central da sala de aula, fonte de todo o conhecimento e único provedor das respostas corretas, compartilhando esta função com todos os alunos.

A proposta deste trabalho foi a de trazer princípios da aprendizagem colaborativa para o campo da avaliação e examinar seus efeitos e sua valia neste contexto. Primeiramente, consideramos o uso da L1 dos alunos e das estruturas de apoio que promoveram em suas interações. Visto que "o diálogo que surge durante a solução de problemas colaborativa é uma representação da atividade cognitiva" (SWAIN; LAPKIN, 1998, p. 322), podemos entender que o uso de L1 é conducente a uma produção mais acurada, pois os aprendizes expõem suas ponderações e as discutem com seu par, refletindo sobre a língua juntos e por consequência melhorando suas competências na L2. Em seguida, observamos os papéis que os alunos assumiram durante a tarefa avaliativa em pares, constatando a inevitável heterogeneidade de funções que os alunos podem desempenhar em regime de colaboração em par. Ao lidar com isso, o professor pode monitorar seus alunos, orientá-los durante a tarefa a dividirem responsabilidades e até mesmo trabalhar com eles a noção de colaboração em outro momento. Por fim, analisamos os fatores afetivos durante a tarefa proposta, e nos atentamos para o aspecto geral de leveza e tranquilidade presente no discurso dos alunos (como evidenciado nos excertos E10 e E11 na análise dos dados: "a gente tá aqui pra [aprender]" e "depois o teacher corrige!"). A colaboração contribuiu para que os alunos desconsiderassem a correção e a nota como elementos de tensão e se sentissem mais dispostos a produzir na língua, realizando um trabalho quiçá melhor.

Finalmente, a partir das considerações aqui feitas, este trabalho alvitra motivar professores a experimentar realizar suas avaliações de forma colaborativa e observar seus 
resultados tanto nas competências linguísticas de seus alunos como em suas afetividades, autonomias e criatividades. Cabe também lançar uma reflexão sobre o real propósito da avaliação, e talvez passar a vê-la sob a ótica da zona de desenvolvimento proximal de Vygotsky, concebendo-a não só como mero meio para se obter um conceito fixo do desempenho do aluno, mas como meio para impulsioná-lo a aprender ainda mais.

\section{Referências}

ANTÓN, M.; DICAMILLA, F. J. Socio-cognitive functions of L1 collaborative interaction in the L2 classroom. The Modern Language Journal, v. 83, n. 2, p. 233-247, 1999.

CRANDALL, J. Cooperative language learning and affective factors. In: ARNOLD, J. (ed.). Affect in language learning. Cambridge: Cambridge University Press, 1999. p. 226-245.

CROKER, R. A. An introduction to qualitative research. In: HEIGHAM, J.; CROKER, R. (eds.). Qualitative research in applied linguistics: a practical introduction. London: Palgrave Macmillan, 2009. p. 3-24.

DONATO, R. Sociocultural contributions to understanding the foreign and second language classroom. In: LANTOLF, J. P. (ed.). Sociocultural theory and second language learning. Oxford: Oxford University Press, 2000. p. 27-50.

FIGUEIREDO, F. J. Q. de. A aprendizagem colaborativa de línguas: algumas considerações conceituais e terminológicas. In: FIGUEIREDO, F. J. Q. de. (org.). A aprendizagem colaborativa de línguas. Goiânia: Ed. da UFG, 2006. p. 11-45.

A aprendizagem colaborativa: foco no processo de correção dialogada. In: LEFFA, V. J. (org.). A interação na aprendizagem das línguas. Pelotas: EDUCAT, 2003. p. 125-157. Fatores afetivos e aprendizagem de línguas: foco na escrita e na correção de erros. In: MASTRELLA-DE-ANDRADE, M. R. (org.). Afetividade e emoções no ensino/aprendizagem de línguas: múltiplos olhares. Campinas, SP: Pontes, 2011. p. 115162.

FORMAN, E. A.; CAZDEN, C. B. Exploring Vygotskian perspectives in education: the cognitive value of peer interaction. In: WERTSCH, J. V. (ed.). Culture, communication and 
cognition: Vygotskian perspectives. Cambridge: Cambridge University Press, 1985. p. 323347.

OLIVEIRA, M. K. O pensamento de Vygotsky como fonte de reflexão sobre a educação. Caderno Cedes. Campinas, SP: n. 35, 2000, p. 11-18.

OXFORD, R. L. Cooperative learning, collaborative learning, and interaction: three communicative strands in the language classroom. The Modern Language Journal. v. 81, n. 4, 1997, p. 443-456.

SCHLATTER, M.; GARCEZ, P. de M.; SCARAMUCCI, M. V. R. O papel da interação na pesquisa sobre aquisição e uso de língua estrangeira: implicações para o ensino e para a avaliação. Letras de hoje. Porto Alegre, n. 137, 2004, p. 345-378.

SILVA, I. M. Uma análise de uma atividade em sala de aula de língua inglesa numa perspectiva interacionista. MOARA - Revista dos Cursos de Pós-Graduação em Letras da UFPA. Belém, n. 11, 1999, p. 39-51.

SWAIN, M.; LAPKIN, S. Interaction and second language learning: two adolescent french immersion students working together. The Modern Language Journal. v. 82, n. 3, 1998, p. 320-337.

SWAIN, M.; BROOKS, L.; TOCALLI-BELLER, A. Peer-peer dialogue as a means of second language learning. Annual Review of Applied Linguistics. Cambridge, v. 22, 2002, p. $171-$ 185.

TUDGE, J; VYGOTSKY, L. S. the zone of proximal development, and peer collaboration: implications for classroom practice. In: MOLL, L. C. (ed.). Vygotsky and education: instructional implications and applications of sociohistorical psychology. Cambridge: Cambridge University Press, 1990. p. 155-172.

VYGOTSKY, L. S. Interação entre aprendizado e desenvolvimento. In: VYGOTSKY, L. S. A formação social da mente. São Paulo: Martins Fontes, 1998. p. 103-119.

O instrumento e o símbolo no desenvolvimento da criança. In: VYGOTSKY, L. S. A formação social da mente. São Paulo: Martins Fontes, 1998. p. 25-40.

WOOD, D.; BRUNER J. S.; ROSS, G. The role of tutoring in problem solving. Journal of Child Psychology and Psychiatry. v. 17, 1976, p. 89-100.

Recebido em 17 de setembro de 2018. 